\title{
Killing me softly: myth in pharmaceutical advertising
}

Tim Scott, Neil Stanford, David R Thompson

In studies of how drug advertising influences doctors' behaviour, little attention is given to visual and linguistic imagery. The authors argue that myth is often deployed in drug adverts to depict exaggerated therapeutic efficacy and that doctors should be aware of this

School of Management, University of St Andrews, Fife KY16 9AJ

Tim Scott senior lecturer

Department of Health Sciences, University of York, York

Neil Stanford research assistant

School of Nursing, Chinese University of Hong Kong, Hong Kong, China David R Thompson director

Correspondence to: T Scott jts1@ st-andrews.ac.uk

BMJ 2004;329:1484-8
Although the influence of research on medical practice has become a key concern, the influence of pharmaceutical advertising in medical journals has received little attention. There is evidence that advertising influences doctors' behaviour more than they might think. ${ }^{1-3}$ Important pockets of research exist in this area but tend to focus on the scientific validity of the text $\mathrm{t}^{4-6}$ and rarely give much attention to visual and linguistic imagery. ${ }^{78}$ If advertising influences beliefs and behaviour and images are used in advertising, then images must contribute to influencing beliefs and behaviour. ${ }^{9}$

One of a range of methods to promote pharmaceutical products, ${ }^{3}{ }^{10}$ advertising in medical journals offers a privileged channel of communication from drug companies to doctors. ${ }^{8}$ Concerns have been expressed about the extent of its influence on prescribing. The industry has been accused of medicalising normal phenomena and promoting drugs as solutions to social problems. ${ }^{12}$ We examine how drug advertisers use images to construct mythical and potentially misleading associations between diseases and products.

\section{Theoretical approach: semiology and mythology}

Interpreting images is a domain of semiology (or semiotics), the general science of signs. Some semiologists argue that we do not primarily consume things but the meanings attached to them. ${ }^{13}$ For example, the Coca Cola brand is less about a carbonated drink than a promise of social identity. A sign is a relation between two terms: a signifier (word, sound, or image) and a signified (a concept). ${ }^{14}$ Any object can become a sign. For example, a black pebble may be used to signify a death sentence in an anonymous vote. ${ }^{15}$ Roland Barthes initiated a branch of semiology termed mythology to study modern myths, often derived from ancient forms or archetypes. ${ }^{15}$ Myth involves two systems of signs: a language-object providing myth with signs as its raw materials, and myth itself-a meta-language, which appropriates the first to convey a specific message.

\section{Methods}

We selected a purposive sample of 60 advertisements from the $B M J$ for 1999-2001 inclusive. We hand searched all issues of the journal and selected exemplars. The sample was not designed for generalising to the population. Each advert was reviewed by two of us to assess its potential contribution to the study. We selected a final sample of 26 adverts promoting drugs for a range of medical conditions, including cardiovascular, gastrointestinal, central nervous system, musculoskeletal, and respiratory diseases. Each was interpreted jointly by discussion, usually over several

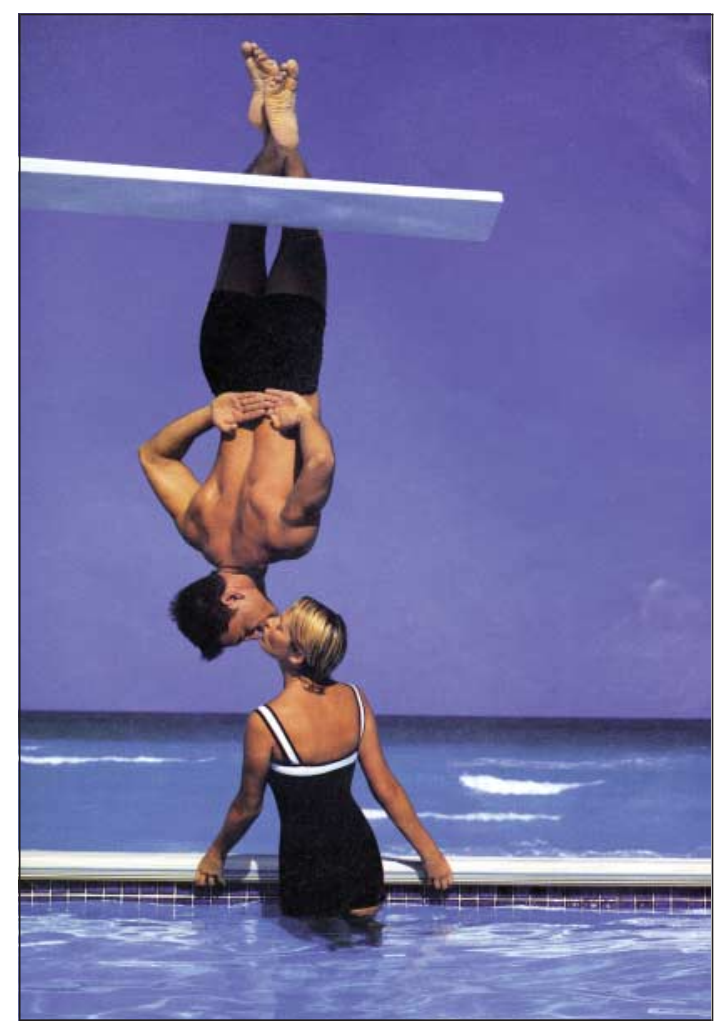

Fig 1 Aprovel: "Approval is what you get when you get it right"

meetings. We present three of our analyses below. Our interpretations are fallible, though they have been tested opportunistically against those of a range of individuals not involved in the study. Other interpretations are possible, and ours should be read as plausible, not factual, accounts.

\section{Results}

Aprovel (hypertension) "Approval is what you get when you get it right"

This image transports the (UK) reader to an exotic location (fig 1). Clear blue sky and calm sea denote a high pressure warm front, suggesting hypertension. The pool's edge divides nature and culture; unbroken surface tension signifying containment and control in contrast to the ocean's unbridled force. The man seems to belong to nature, the woman to culture (beauty and the beast?). Legs hooked over the board, he hangs apishly, body massively contracted, even his extremities. This suggests an association between hypertension and inversion: both increase blood pressure in the brain, neither should be maintained for long. The athletic stunt, like the medical condition, seeks attention, which comes as a kiss of approval (or Aprovel). 


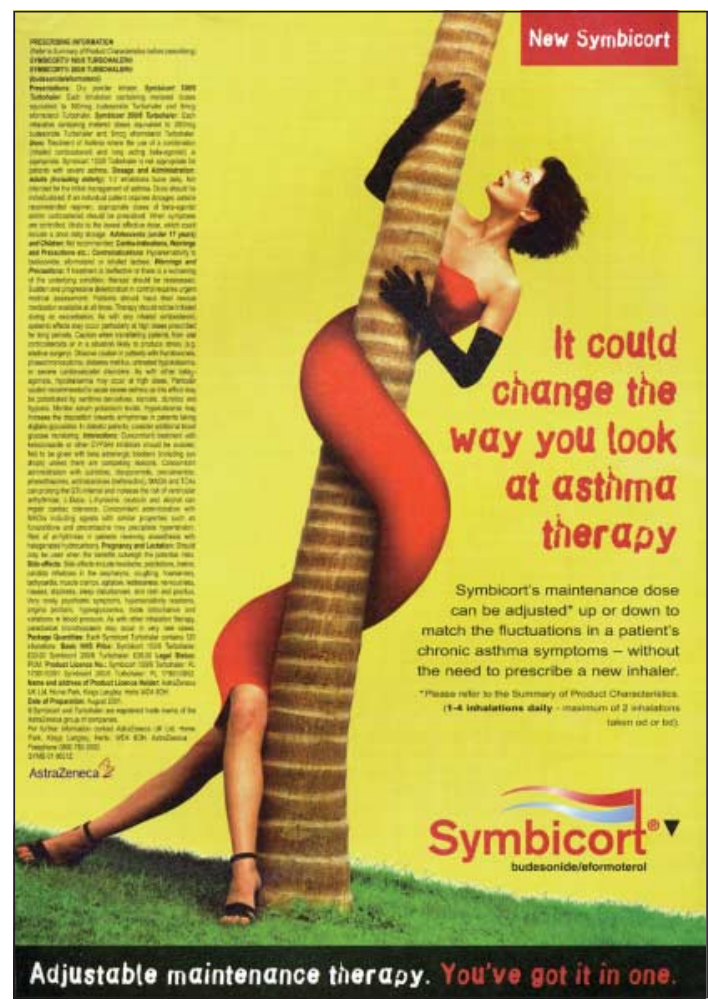

Fig 2 Symbicort: "Adjustable maintenance therapy. You've got it in one"

The woman is also quite taut. Her grip on the pool rim shows she is not lifting herself up but apparently resisting an uplifting force. This is another allusion to surface tension: if you imagine the board dipping into the pool and slowly lifting out, the kissing couple represent a droplet that clings and stretches between board and surface until it breaks. The kiss is a tension, joining and separating two bodies. It marries natural impulse to its acculturated expression, passion and institution, mediating between nature wild and uncontrolled (untreated hypertension) and nature tamed and pacified (medicated). The man personifies hypertension, the woman Aprovel. An explicit association between Aprovel and hypertension is linked to a series of parallel tensions: atmospheric, postural, muscular, surface, sexual. Each is paired with an appropriate response: for hot weather, bathing; for inversion, reversion; for contraction, relaxation; for a perturbed ocean, the swimming pool; for man, woman; for nature, culture; for hypertension, Aprovel. The advert naturalises an association between Aprovel and hypertension by implying their membership of an order of natural couplings. It is a sophisticated version of a generic advertising myth: for indication $\mathrm{Y}, \operatorname{drug} \mathrm{X}$ is the natural choice.

\section{Symbicort (asthma) "Adjustable maintenance therapy. You've got it in one"}

Grotesquely distorted into a mnemonic S, Symbicort snake woman embodies an alliterative, sibilant association between Symbicort, snake, sex, and other provocative S-words (symbol, stretch, slither, sensual, slave, suck, etc) (fig 2). The image signifies a graduated scale ("Symbicort's maintenance dose can be adjusted up and down"). Aggressive colours repeat the brand name and suggest eroticism. Red cocktail dress and lipstick, long black gloves and shoes, hair swept back and roguishly un-brushed. She is sensuous and monstrous; woman metamorphosing to reptile; a hybrid symbol of disease and sex.

Evoking Plato's pharmakon, signifying both remedy and poison, ${ }^{16}$ snake woman signifies therapy and disease; she soothes and constricts. The palm trunk signifies a trachea, she its constricting inflammationthe physiology of asthma. Her feet are rooted in the ground, legs splayed like vine stems (poison ivy?). These further confuse the erotic and pathological. Redness signifies inflammation of lust and immune response. She entwines a phallus, stroking its shaft, head inclined, lips parted-and simultaneously strangles her lover.

The image also invokes the caduceus-snake entwined staff, symbol of Aesculapius, Greco-Roman god of medicine, and carried by Mercury. Linked to the underworld, the snake is a mediator between one way of life and another. The caduceus symbolises medicine as mediator between illness and recovery. The explicit myth is about changing the way we conceive a disease and its treatment. It is underpinned by a more remarkable transformation of woman and snake that can hold the reader's gaze, fascinated by the sight of a sensuous woman and boa constrictor becoming one another.

\section{Taxotere (cancer) "Leading the fight against} advanced breast cancer"

An industry award winner in 2001, this example (fig 3) prompted debate in the $B M J$ about what some saw as inappropriate eroticism. ${ }^{17}$ It is a tableau of Delacroix's Liberty Leading the People (fig 4). Pink silk flags substitute for sabres, muskets, pistols, and tricolour in the original painting to evoke the pink ribbons of the (drug industry sponsored) breast cancer awareness campaign. It

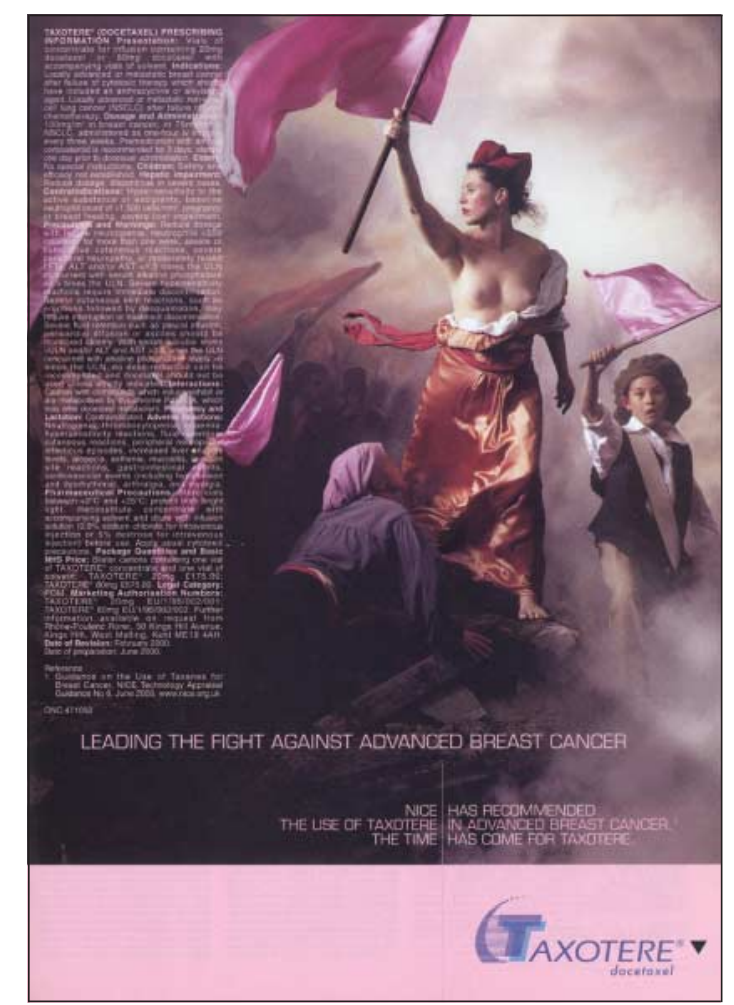

Fig 3 Taxotere: "Leading the fight against advanced breast cancer" 
implies that commitment and belief are more important than blades and bullets in the fight against breast cancer, a message simplified by removing the naked and dead littering the foreground of original.

A triumphant woman lofts her flag, her fine dress pulled down, revealing her breasts. An armpit, site of lymph nodes involved in metastasis, is exhibited. She is strong and beautiful, but her eroticism is restrained, her nipples toned down, their paleness an attenuated sign of disease. Baring her breasts suggest a political statement about divesting the shame and secrecy associated with breast cancer.

The revolutionary stance echoes positions adopted during clinical examinations. Her impassive face and sideways glance recall the blank expression and posture of one undergoing mammography. An association is made between gazing at art and medical images. Her muscular foot is planted on rock (solid symbol of medical progress), and her expression is dignified in adversity. The inspirational theme is reinforced by a defeated woman kneeling at her feet, drawing strength from Liberty "Leading the fight against advanced breast cancer." The battle metaphor for cancer has been discussed extensively. ${ }^{18}$

Treatment for advanced breast cancer can give mothers a few extra months to spend with young children. Beside Liberty a boy, figure of pathos, echoes her posture and waves his small flag. He signifies the hopes of mothers and their children affected by breast cancer and its impact on families. The top-hatted woman (a man in the original painting) is ambiguous, perhaps signifying a male or female partner, but also an institutional revolution, overthrowing outmoded attitudes that some may associate with the ancien régime of a male dominated medical establishment, and an ascendance of feminine values and patient advocacy in cancer care. A hackneyed theme, victory against cancer, but beautifully executed and interwoven with a modern mythology of patient advocacy, both having at least a tenuous foothold in the recent history of the disease. They in turn are associated with a mythology of liberation from oppression, an age of reason and

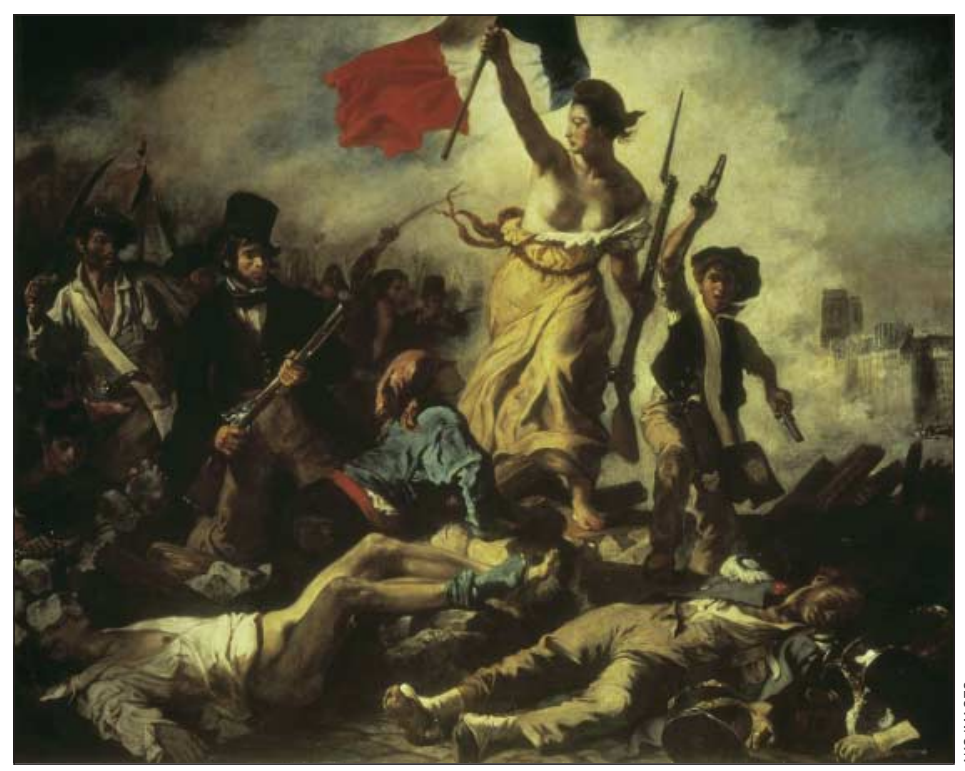

Fig 4 Liberty Leading the People by Eugène Delacroix, 1830, in the Musée du Louvre, Paris

\section{Summary points}

Advertising in medical journals provides a privileged channel of communication between the pharmaceutical industry and clinicians

A critical study of imagery employed in drug adverts reveals it to be one the most powerful weapons of drug promotion

Drug advertising uses strong imagery to fabricate mythical associations between medical conditions and branded drugs

Drug advertising manipulates readers' perceptions by subtle appeal to ancient and modern mythological foundations of humanism and Western psychology

Clinicians claiming immunity to drug advertising greatly underestimate some advertising agencies, whose skill they should respect as comparable to their own

democracy, the French Revolution and the start of the Enlightenment.

\section{Discussion}

Our analysis suggests that myth is often deployed in drug advertising to depict exaggerated therapeutic efficacy: armed with such drugs, the clinician can liberate patients from the oppression of disease and restore them to normality. With medicine as their alibi, ${ }^{15}$ advertisers exploit the nude. Accused of eroticism, the company, agency, or reader has an alibi in physiology. What could be more natural than to deploy a breast image to promote Taxotere? Eroticism thrives on such ambiguity. For an extraordinary moment, the seminaked patient is transformed into an aesthetic nude, object of a thoroughly non-medical gaze, though the clinical glance may quickly reassert itself. Mythology transports the clinician into a wider sociocultural context than that of medicine alone. Viewing exotic or erotic scenes derived from "old masters," the reader is relocated from office to gallery, obtaining visual relief from the clinical grind.

In law and science, words are precise and accountable, justified by evidence. In advertising, the image is ambiguous and unaccountable. It makes its "killing" (an aggressive metaphor for selling) softly. Thus we arrive at the very principle of myth: to transform history into nature. ${ }^{15}$ Associations between diseases and drugs are made to seem natural, unmotivated by commercial interest. The manifold couplings conveyed in the Aprovel advert show the principle well. Its administration for hypertension seems as natural as kissing, bathing, and other variations on a coupling theme. Condition and brand are presented as belonging to a higher logical order of things that belong to each other. To naturalise is also to neutralise or "dis-interest" the intention to promote. 


\section{Policy implications}

The aim of our research is to raise awareness of mythology in drug advertising, which may lead to doctors being better able to resist misleading promotion. This implies a need for closer regulation of journals as a privileged channel of communication from the drug industry to clinicians. It also highlights a rhetorical mode of persuasion in contrast with rational argument. By recognising that clinicians are also consumers, researchers and regulators could learn from advertisers how to change beliefs and behaviour more effectively than by reason alone. ${ }^{19}$

We thank Iain Chalmers and Barbara Mintzes for supporting the idea of this study, staff and students at the University of California School of Public Health and the University of St Andrews School of Management for comments on seminar presentations of the study, Iain Munro for theoretical advice, Alan Chandler and Peter Mansfield for suggested revisions to earlier drafts, and colleagues at the University of York for support and encouragement.

Contributors: TS was responsible for the conception, design, establishment, analysis, and writing up of the study. NS contributed to the conception, design, establishment, analysis, and writing. DRT contributed to the design and establishment, analysis, and writing.

Funding: The study was funded by a grant from the University of York Innovation Fund supplemented by the Department of Health Sciences. Some of TS's work was done during a Harkness Fellowship in Health Policy 2002-3, awarded by the Commonwealth Fund of New York.

Competing interests: None declared.
1 Lexchin J, Mansfield P, Mintzes B, Medawar C, Hamdan Z. Drug promotion database: WHO Department of Essential Drugs and Medicines Policy, Health Action International Europe, Universiti Sains Malaysia. www.drugpromo.info/ (updated 2002, accessed 2 Nov 2004).

2 Mansfield PR. Healthy Skepticism's new AdWatch: understanding drug promotion. Med J Aust 2003;179:644-5.

3 Sutherland M. Advertising and the mind of the consumer: what works, what doesn't and why. Sydney: Allen and Unwin, 1993.

4 Mansfield PR. Classifying improvements to drug marketing and justifications for claims of efficacy. Int J Risk Safety Med 1991;2:171-84.

5 Wade V, Mansfield PR, McDonald P. Drug companies evidence to justify advertising. Lancet 1989;ii:1261-3.

6 Wilkes MS, Doblin BH, Shapiro M. Pharmaceutical advertisements in leading medical journals: experts' assessments. Ann Intern Med 1992;116:912-9

7 Goldman R, Montagne M. Marketing "mind mechanics": decoding antidepressant advertisements. Soc Sci Med 1986;22:1047-58.

8 Hutcheon L, Hutcheon M. Medical "mythologies": a semiotic approach to pharmaceutical advertising. Queen's Q 1987;94:904-16.

9 Mansfield PR. Garai's challenge: the 40th anniversary of the inspiration for Healthy Skepticism. Healthy Skepticism International News 2003;1:10 (www.healthyskepticism.org/editions/2003/10.asp).

10 Morgan S, Barer M, Evans R. Health economists meet the fourth tempter: drug dependency and scientific discourse. Health Econ 2000;9:659-67.

11 Scott D, Ferner R. "The strategy of desire" and rational prescribing. $\mathrm{Br} \mathrm{J}$ Clin Pharmacol 1994;37:217-9.

12 Stimson GV. The message of psychotropic drug ads. Journal of Communications 1975;25:153-60.

13 Baudrillard J. La Societe de Consommation. Paris: Gallimard, 1970.

14 Saussure F de. Course in general linguistics. London: Duckworth, 1983.

15 Barthes R. Mythologies. London: Vintage, 1972/1957.

16 Derrida J. Dissemination. Chicago: University of Chicago, 1981

17 Farrell L. Ads: O Liberty! what crimes are committed in thy name! $B M J$ 2000;321:578.

18 Sontag S. Illness as a metaphor and AIDS and its metaphors. London: Penguin, 1991.

19 Landgren F, Harvey K, Mashford M, Moulds R, Guthrie B, Hemming M. Changing antibiotic prescribing by educational marketing. Med J Aust 1988;149:595-9.

\section{Commentary: Accepting what we can learn from advertising's mirror of desire}

Peter Mansfield

\begin{abstract}
'Now can you think what the Mirror of Erised shows us all?'. .

Harry thought. Then he said slowly, 'It shows us what we want ... whatever we want...

'Yes and no,' said Dumbledore quietly. 'It shows us nothing more or less than the deepest, most desperate desire of our hearts.'
\end{abstract}

J K Rowling, Harry Potter and the Philosopher's Stone

The commercial success of the Harry Potter books, despite literary limitations, shows both the power of promotion and the power of imagery that taps deeper meanings from metaphors and ancient myths. Readers of the first Harry Potter book are challenged to decode the inscription on the magical Mirror of Erised to reveal the meaning: "I show not your face but your heart's desire." Drug advertising is also a mirror to our souls that can teach us much about ourselves. ${ }^{2}$ Competition among drug companies to increase sales creates selective pressure for the evolution of advertising that accurately reflects how healthcare professionals really make decisions. Scott and colleagues have decoded advertising's mirror of desire. ${ }^{13}$ We may not want to believe what the mirror shows us, nor agree with the details of their decoding, but acceptance of their main messages may lead to major improvements in medical decision making by reducing our vulnerability to adverse influence.

Many healthcare professionals deny that we are influenced by drug promotion because to admit other- wise would insult our intelligence ${ }^{3}$ and hurt our self esteem. Some of us concede that some of our peers are vulnerable, but not ourselves. By contrast, drug companies know that combinations of promotional techniques, including carefully chosen images that appeal to our desires, are effective for increasing sales. ${ }^{4}$ Images influence even the cleverest people by sneaking in under the radar of our verbal intelligence. ${ }^{2}$ The first step to overcoming this vulnerability is to dispel our illusion of invulnerability by accepting that we all have human limitations. ${ }^{5}$

Many of us have been misled into overconfidence about drugs such as cyclo-oxygenase- 2 inhibitors, antidepressants, and misnamed "hormone replacement therapy." To avoid being misled again and again, we need a better understanding of how promotional techniques work as a foundation both for better regulation of promotion and for better training for healthcare professionals. ${ }^{6}$ Harnessing promotional techniques may also enable more effective dissemination of evidence based medicine. My informal marketing research suggests that the metaphors in this commentary will work like magic for many readers but not for all.

Scott et al's article helps us by studying how symbols and signs in advertising images can create powerful meanings by tapping into the myths we use to understand our world, our lives, and ourselves. Images
Healthy Skepticism, 34 Methodist Street, Willunga, $5172 \mathrm{SA}$, Australia Peter Mansfield director

peter@ healthyskepticism.org 